УДК 374 (045)

13.00.00 Педагогические науки

РЕЗУЛЬТАТЫ ЭМПИРИЧЕСКОГО

ИССЛЕДОВАНИЯ ФОРМИРОВАНИЯ ДИДАКТИЧЕСКОЙ КОМПЕТЕНТНОСТИ СТУДЕНТОВ ПЕДАГОГИЧЕСКОГО ВУЗА В ПРОЦЕССЕ САМОСТОЯТЕЛЬНОЙ РАБОТЫ

Мовсесян Жанна Агасиевна

аспирант

SPIN-код автора: 5690-2657

Мордовский государственный педагогический институт им. М. Е. Евсевьева, Саранск, Россия

В статье рассматривается вопрос формирования дидактической компетентности студентов педагогического вуза в процессе самостоятельной работы. В данной статье описываются некоторые результаты эмпирического исследования по формированию дидактической компетентности студентов педагогического вуза в процессе самостоятельной работы

Ключевые слова: ДИДАКТИЧЕСКАЯ КОМПЕТЕНТНОСТЬ, СТУДЕНТ

ПЕДАГОГИЧЕСКОГО ВУЗА, САМОСТОЯТЕЛЬНАЯ РАБОТА, КРИТЕРИЙ, РЕЗУЛЬТАТ

Doi: 10.21515/1990-4665-131-036
UDC 374 (045)

Pedagogical sciences

\section{RESULTS OF THE EMPIRICAL STUDY OF FORMING THE DIDACTIC COMPETENCE OF STUDENTS OF A PEDAGOGICAL UNIVERSITY IN THE PROCESS OF INDEPENDENT WORK}

Movsesyan Zhanna Agasievna

Postgraduate student

RSCI SPIN-code: 5690-2657

Mordovian State Pedagogical Institute, Saransk, Russia

The article deals with the formation of the didactic competence of students at a pedagogical university in the process of independent work. This article describes some results of an empirical study on the formation of the didactic competence of students at a pedagogical university in the process of independent work

Keywords: DIDACTIC COMPETENCE, STUDENT OF PEDAGOGICAL UNIVERSITY, SELF-STUDY, CRITERION, RESULT

В условиях модернизации системы образования повышаются требования, предъявляемые к профессиональной подготовке выпускников педагогического вуза. Для формирования компетентного учителя необходимо качественное образование, которое в настоящее время связывают не столько с усвоением знаний, сколько с умением приобретать новые знания, с формированием дидактической компетентности.

Анализ ряда исследований (Е. В. Бережнова, Л. М. Перминова, И. М. Осмоловская, $\quad$ А. И. Уман, Т. И. Шукшина $\quad$ и $\quad$ др.) позволил сформулировать определение дидактической компетентности студентов педагогического вуза как интегративного качества личности, включающего совокупность личных и профессиональных ценностей и мотивов, знаний содержательных и процессуальных основ процесса 
обучения, a также дидактических умений, способствующих осуществлению дидактической деятельности.

В структуру дидактической компетентности студентов педагогического вуза входит совокупность следующих компонентов: аксиологический (мотивация к учебной деятельности, совокупность личностных и профессиональных качеств: потребность к познавательной активности, проявление самостоятельности в процессе познания, а также ряд личных и профессиональных ценностей и т.д.); гностический (наличие дидактических знаний сущности процесса обучения как целостной системы и возможности их использования); операџионно-технологчческий (наличие дидактических умений и способов деятельности в качестве наиболее эффективных при работе с обучающимися); рефлексивнылй компонент (способность оценивать свои результаты, ошибки собственной деятельности, способность к саморегуляции). Каждый компонент дидактической компетентности характеризуется аспектами его проявления и рассматривается в контексте осуществления будущей профессиональной деятельности.

Экспериментальное исследование осуществлялось на базе ФГБОУ ВО «Мордовский государственный педагогический институт имени М. Е. Евсевьева» в г. Саранске. В исследовании приняли участие 125 студентов второго курса, обучающихся по направлению подготовки «Педагогическое образование» и 25 экспертов из числа преподавателей кафедр педагогики и педагогики дошкольного и начального образования МГПИ, а также учителей образовательных организаций.

В рамках первого этапа эксперимента был выявлен исходный уровень сформированности дидактической компетентности студентов педагогического вуза с помощью методик, а именно: методика Т. И. Ильиной «Мотивация обучения в вузе», адаптированная анкета по оценке уровня сформированности дидактических умений в интерпретации 
H. В. Кузьминой, методика диагностики индивидуальной меры выраженности рефлексивности А. В. Карпова и др. Результаты констатирующего этапа свидетельствуют о том, что более чем у $56 \%$ респондентов уровень сформированности дидактической компетентности характеризуется как низкий.

В русле исследуемой проблемы был проведен формирующий эксперимент, где были верифицированы педагогические условия, способствующие результативному функционированию модели формирования дидактической компетентности студентов педагогического вуза в процессе самостоятельной работы в ЭГ: 1) внедрение в учебный процесс мотивационных способов активизации самостоятельной работы, направленных на формирование дидактической компетентности студентов педагогического вуза; 2) обеспечение организации самостоятельной работы студентов педагогического вуза через информационнообразовательную среду дидактической направленности; 3) включение студентов педагогического вуза в самостоятельную работу через выполнение компетентностно-ориентированных разноуровневых учебных заданий; 4) осуществление контроля за результатами самостоятельной работы студентов педагогического вуза в формировании дидактической компетентности. В контрольной группе осуществлялся стандартный процесс учебно-воспитательной работы.

На контрольном этапе был проведен сравнительный анализ результатов исследования, полученных до формирующего этапа и по итогам его проведения. Сравнивая данные КГ и ЭГ, отметим их небольшое изменение. В ЭГ из низкого $34 \%$ респондентов перешли в средний и высокий уровни, из среднего уровня $48 \%$ респондентов достигли высокого. Анализируя полученные данные, можно сделать вывод, что уровень мотивационно-ценностного критерия дидактической 
компетентности студентов педагогического вуза находится на высоком уровне.

При анализе данных на контрольном этапе по когнитивному критерию дидактической компетентности студентов использовался электронный тест по теории обучения, разработанный преподавателями кафедры педагогики МГПИ. Итоговое тестирование показало, что у студентов обогатились дидактические знания, которые позволили им повысить уровень знаний в области теории обучения, достаточно уверенно и достойно отвечать на вопросы после изучения данного раздела. На контрольном этапе эксперимента по когнитивному критерию респондентов с низким уровнем оказалось всего $17 \%$, со средним уровнем - 34\% и с высоким уровнем 49\%, что отражает повышение уровня дидактических знаний студентов педагогического вуза.

Анализ уровня сформированности операционно-технологического критерия дидактической компетентности студентов показал, что с низким уровнем оказалось всего 21\%, со средним уровнем - 29\%, с высоким уровнем - 50\%, говорящее о значительном повышении уровня дидактических умений студентов педагогического вуза.

Анализ полученных результатов КГ и ЭГ по оценочному критерию дидактической компетентности студентов показал, что на контрольном этапе респондентов с низким уровнем оказалось $17 \%$, со средним уровнем - 50\%, с высоким уровнем - 33\%, что отражает повышение уровня рефлексивности и самооценки в предстоящей педагогической деятельности. Сравнивая данные КГ и ЭГ до и после проведения эксперимента по оценочному критерию дидактической компетентности студентов педагогического вуза, следует отметить незначительное изменение результатов КГ после заключительной диагностики и существенное изменение результатов ЭГ после проведения эксперимента. 
Обобщенные результаты исследования, отражающие уровень сформированности дидактической компетентности студентов педагогического вуза в КГ и ЭГ представлены в таблице 1.

таблица 1

Данные сравнения в уровне сформированности дидактической компетентности студентов педагогического вуза в ЭГ и КГ, \%

\begin{tabular}{|c|c|c|c|c|}
\hline \multirow{2}{*}{$\begin{array}{c}\text { Уровни } \\
\text { дидактической } \\
\text { компетентности }\end{array}$} & \multicolumn{4}{|c|}{ Количество, \% } \\
\cline { 2 - 5 } & Экспериментальная группа & Контрольная группа \\
\hline Низкий & 56,6 & 17,5 & 55,5 & после \\
\hline Средний & 32,5 & 37,5 & 33,3 & 36,3 \\
\hline Высокий & 11,6 & 45 & 11,5 & 11,8 \\
\hline
\end{tabular}

Исходя их представленных данных, подчеркнем небольшое изменение в полученных результатах КГ и значительное изменение уровня сформированности дидактической компетентности студентов педагогического вуза ЭГ.

Таким образом, контрольный этап эксперимента показал положительную динамику во всех выборках, однако наблюдаемый качественный и количественный прирост выше в экспериментальной группе $(84 \%)$. Большая разница между КГ и ЭГ свидетельствует об эффективности верифицированных педагогических условий результативного функционирования модели формирования дидактической компетентности студентов педагогического вуза в процессе самостоятельной работы.

В ходе экспериментальной работы по верификации педагогических условий результативного функционирования модели формирования дидактической компетентности студентов педагогического вуза в процессе самостоятельной работы было установлено, что по выделенным критериям студенты ЭГ достигли более значимых результатов, чем студенты КГ, что подтвердилось при проведении количественного анализа полученных данных с использованием статистического критерия Пирсона $\left(\chi^{2}\right)$. 
Результаты, полученные в ходе экспериментальной работы, доказали, что разработанная модель формирования дидактической компетентности студентов педагогического вуза в процессе самостоятельной работы и верифицированные педагогические условия ее результативного функционирования являются эффективными.

\section{Литература:}

1. Гладкая, И.В. Становление понятия «профессиональная компетентность» в теории профессионального образования / И. В. Гладкая // Человек и образование. 2011. - № 2. - С.130-134.

2. Шапарь, В. Б. Практическая психология. Инструментарий : учеб. пособие для вузов / В. Б. Шапарь, А. В. Тимченко, В. Н. Швыдченко. - Ростов н/Д : Феникс, 2002. $688 \mathrm{c}$.

3. Шукшина, Т. И. Педагогическая олимпиада как гуманитарная технология формирования профессиональной компетентности / Т. И. Шукшина, Т. В. Татьянина // Высшее образование сегодня. - 2009. - № 11. - С. 33-37.

4. Шукшина, Т. И. Самостоятельная работа в формировании профессиональной компетентности бакалавров педагогического образования / Т.И. Шукшина, Ж.А. Мовсесян, И.И. Парватова, П.Ю. Соколова // Гуманитарные науки и образование. - 2016. - № 3. - С. 72-77., с. 74.

5. Шукшина, Т. И. , Мовсесян, Ж. А. Педагогические условия формирования дидактической компетентности будущих учителей в процессе самостоятельной работы / Т. И. Шукшина, Ж. А. Мовсесян // Вестник Челябинского государственного педагогического университета. - 2016. - № 10. - С. 122 - 130.

\section{References}

1. Gladkaja, I.V. Stanovlenie ponjatija «professional'naja kompetentnost'»v teorii professional'nogo obrazovanija / I. V. Gladkaja // Chelovek i obrazovanie. - 2011. - № 2. - S.130-134.

2. Shapar', V. B. Prakticheskaja psihologija. Instrumentarij : ucheb. posobie dlja vuzov / V. B. Shapar', A. V. Timchenko, V. N. Shvydchenko. - Rostov n/D : Feniks, 2002. $-688 \mathrm{~s}$.

3. Shukshina, T. I. Pedagogicheskaja olimpiada kak gumanitarnaja tehnologija formirovanija professional'noj kompetentnosti / T. I. Shukshina, T. V. Tat'janina // Vysshee obrazovanie segodnja. - 2009. - № 11. - S. 33-37.

4. Shukshina, T. I. Samostojatel'naja rabota $v$ formirovanii professional'noj kompetentnosti bakalavrov pedagogicheskogo obrazovanija / T.I. Shukshina, Zh.A. Movsesjan, I.I. Parvatova, P.Ju. Sokolova // Gumanitarnye nauki i obrazovanie. - 2016. № 3. - S. 72-77., s. 74.

5. Shukshina, T. I. , Movsesjan, Zh. A. Pedagogicheskie uslovija formirovanija didakticheskoj kompetentnosti budushhih uchitelej v processe samostojatel'noj raboty / T. I. Shukshina, Zh. A. Movsesjan // Vestnik Cheljabinskogo gosudarstvennogo pedagogicheskogo universiteta. - 2016. - № 10. - S. 122 - 130. 